\title{
La protección social y medioambiental en las relaciones comerciales entre la Unión Europea y América Latina
}

Armando Alvares Garcia Júnior*

*Profesor de derecho internacional público, derecho del comercio internacional y estructura económica mundial en la Universidad Internacional de la Rioja, España. armando.alvares@unir.net

Recebido em: 15/08/2012 - Aprovado em: 15/10/2012 - Disponibilizado em: 30/12/2012

Resumen: Desde 1971 el bloque europeo concede preferencias comerciales a los países en desarrollo. Para poder acceder al mercado europeo con mayores facilidades arancelarias, el actual régimen jurídico adoptado en la Unión Europea establece como condición la adopción y efectiva aplicación de diversos tratados internacionales de protección social y medioambiental. Aunque sea políticamente correcta, esa condición puede ocultar una importante barrera comercial.

Palabras clave: Unión Europea, América Latina, Sistema de Preferencias Generalizadas, Comercio Internacional, Barreras comerciales.

\section{The social and environmental protection in trade relations between the European Union and Latin America}

\begin{abstract}
Since 1971 the European bloc granted trade preferences to developing countries. To access the European market with greater ease tariff, the current legal regime adopted in the European Union established as a condition the adoption and implementation of international treaties of social and environmental protection. Although it is politically correct, this condition may hide an important trade barrier.
\end{abstract}

Keywords: European Union, Latin America, GSP, International Trade, Trade Barriers.

\section{EL SISTEMA DE PREFERENCIAS GENERALIZADAS EN LA UNIÓN EUROPEA (SPG)}

El bloque europeo concede preferencias comerciales a los países en desarrollo desde 1971. La finalidad, según el derecho comunitario, es el fomento y la consolidación de las políticas de gobernanza y desarrollo sostenible en los países beneficiarios de las concesiones.

Ese trato jurídico está basado en la denominada "cláusula de habilitación" adoptada durante la Ronda GATT de 1979, que autorizaba a sus miembros conceder tratamientos diferenciales y más favorables a los países en desarrollo.
El sistema de preferencias generalizadas (SPG), aprobado en la reunión del Parlamento Europeo de 13 de junio de 2012, propone definir y emprender acciones que fomenten el desarrollo económico, social y medioambiental sostenible de los países en vías de desarrollo, con el objetivo primario de erradicar la pobreza y generarles ingresos adicionales con el acceso preferencial al mercado europeo.

El SPG está constituido por un régimen general y dos regímenes especiales:

1) El régimen general se dirige a todos los países en vías de desarrollo que se encuentran en una fase similar de desarrollo económico. Están excluidos los países que el Banco Mundial 
considere que tenga ingresos elevados y cuyas exportaciones sean suficientemente diversificadas;

2.a) El régimen especial de estímulo al desarrollo sostenible $y$ a la gobernanza (el denominado $S P G \quad P l u s$ ), que incorpora preferencias arancelarias adicionales, está basado en el concepto integral de desarrollo sostenible reconocido en diversos convenios e instrumentos internacionales.

2.b) El régimen especial a favor de los países reconocidos y clasificados como menos desarrollados por las Naciones Unidas, beneficiarios de concesiones de acceso libre de derechos arancelarios al mercado comunitario. Ese régimen es conocido como TMA (Todo menos armas) y en ello se concede exención total de aranceles a todos los productos, salvo las armas.

Los regímenes especiales deberían concederse a los países en desarrollo vulnerables debido a su falta de diversificación y a su insuficiente integración en el sistema de comercio mundial y orientarse a la promoción de un mayor crecimiento económico respondiendo positivamente a la necesidad de desarrollo sostenible.

El propósito europeo sería ayudarles a asumir las cargas y responsabilidades derivadas de la ratificación y efectiva aplicación de convenios internacionales fundamentales sobre derechos humanos y laborales, protección del medio ambiente y gobernanza.

2. DERECHOS HUMANOS, LABORALES Y PROTECCIÓN MEDIOAMBIENTAL EN LAS RELACIONES INTRACOMUNITARIA Y EXTRACOMUNITARIA

El desarrollo y la consolidación de los temas sociales en la Unión Europea son el resultado de un largo proceso histórico iniciado después de la Segunda Guerra Mundial.

Actualmente existen diversas iniciativas institucionales relacionadas con: a) el proceso de integración social, b) las políticas de prevención y lucha contra la pobreza y la exclusión social, c) la lucha contra la discriminación social y racial, d) la igualdad entre mujeres y hombres, e) la modernización de los mercados laborales y los sistemas de protección social, f) iniciativas para mejorar las condiciones de trabajo etc.

Los derechos humanos, laborales y la protección medioambiental son objeto de atención por parte de distintas instituciones de la Unión Europea en el ámbito intracomunitario y por parte de sus países miembros en el ámbito nacional. Tanto las legislaciones nacionales como las normas comunitarias buscan consolidar esos derechos.

En lo que concierne a las relaciones comerciales entre la Unión Europea y terceros países (extracomunitarios), se 
ha cristalizado fuertemente en las discusiones institucionales (como en el ámbito del Parlamento Europeo), la importancia de la adopción y efectivo cumplimiento de patrones mínimos de protección social, laboral y medioambiental por parte de los socios o potenciales socios comerciales del bloque europeo relativamente a la concesión y permanencia de las preferencias arancelarias.

Ese estándar mínimo de protección está plasmado en un conjunto de instrumentos internacionales como, por ejemplo:

a) La Declaración de las Naciones Unidas sobre el Derecho al Desarrollo, de 1986.

b) La Declaración de Río sobre el Medio Ambiente y el Desarrollo, de 1992.

c) La Declaración de la Organización Internacional del Trabajo relativa a los Principios y Derechos Fundamentales en el Trabajo, de 1998.

d) La Declaración del Milenio de las Naciones Unidas, de 2000.

e) La Declaración de Johannesburgo sobre el Desarrollo Sostenible, de 2002.

f) Los Convenios n. 87, 98, 100, 111, 138 y 182 de la Organización Internacional del Trabajo.

Las normas laborales básicas que figuran como condicionantes en el sistema de preferencias arancelarias generalizadas comprenden ocho convenciones de la Organización Internacional del Trabajo (OIT) relativas a las cuatro áreas a las que se refiere la Declaración de 1998 de la OIT sobre los principios y derechos fundamentales en el trabajo: 1) la eliminación de todas las formas de trabajo forzado $\mathrm{u}$ obligatorio, 2) la libertad de asociación, la libertad sindical y el reconocimiento efectivo del derecho de negociación colectiva, 3) la eliminación de la discriminación en materia de empleo y ocupación y 4) la abolición del trabajo infantil.

La Declaración insta a los Estados Miembros de la OIT a respetar y promover los principios y derechos comprendidos en esas cuatro categorías, hayan o no ratificado los convenios pertinentes.

Relativamente a la protección medioambiental, la condicionante presente en el sistema de preferencias arancelarias generalizadas de la Unión Europea es el cumplimiento de las normas internacionales referentes a la gestión sostenible de los bosques tropicales.

En el ámbito de la Unión Europea, el sistema de preferencias arancelarias generalizadas establece el respecto a esas normas internacionales específicas como condicionantes para que distintos países puedan acceder al mercado comunitario en situaciones comparativamente más ventajosas. El régimen general abarca aproximadamente 7.000 productos. 


\section{ANTAGONISMOS POLÍTICOS EN RELACIÓN A LA INCLUSIÓN DE LA PROTECCIÓN SOCIAL Y MEDIOAMBIENTAL EN EL ÁMBITO DEL COMERCIO INTERNACIONAL}

Aunque cumplan un papel relevante en relación al fomento de la protección social en terceros países interesados en exportar al mercado comunitario, las condicionalidades presentes en el sistema de preferencias arancelarias generalizadas pueden representar verdaderas barreras no arancelarias y contrariar los propios principios básicos de liberalización progresiva del comercio internacional adoptados por la Organización Mundial del Comercio, entidad que tiene a la Unión Europea como uno de sus miembros más activos e importantes desde el $1^{\circ}$ de enero de 1995.

En diferentes ocasiones las discusiones sobre los temas sociales en el comercio han sido diplomáticamente desplazados para la Organización Internacional del Trabajo, que denomina a esos temas "la dimensión social del comercio".

Sin embargo, solamente en el ámbito de la OMC el tema podría adquirir relevancia suficiente para eventualmente incorporarse como barrera no arancelaria al comercio internacional. Desde luego, la Unión Europea ha adoptado la firme posición de que la falta de protección social, laboral o medioambiental no puede constituirse en ventaja comparativa en el comercio internacional de bienes y servicios.
El impase de la Ronda Doha de la Organización Mundial del Comercio, iniciada en el 2001, tiene su origen en posicionamientos antagónicos relacionados con la apertura de los mercados al comercio internacional.

En lo que concierne a las relaciones comerciales entre la Unión Europea y América Latina, a groso modo, es posible afirmar que el bloque europeo pretende incrementar la exportación de manufacturas al mercado latinoamericano, al paso que los países latinoamericanos pretenden incrementar la exportación de bienes primarios al mercado europeo.

Por otro lado, los gobiernos latinoamericanos desean preservar, consolidar, desarrollar y diversificar sus industrias, muchas de ellas incipientes o dependientes de las criticadas compras gubernamentales al paso que los gobiernos europeos desean mantener lo más intacto posible ciertos sectores sensibles, como la agricultura, que logra captar aproximadamente la mitad del presupuesto comunitario.

La sensibilidad de los productos viene determinada por la situación de los sectores de la Unión Europea que fabrican estos mismos productos que, todavía, requieren importante protección aduanera ${ }^{1}$.

$\mathrm{Si}$ por un lado los países latinoamericanos gozan de ventajas comparativas (tierras, condiciones climatológicas etc.) en relación a la

\footnotetext{
${ }^{1}$ La propuesta actual consiste en la suspensión de los derechos arancelarios para los productos no sensibles y la aplicación de una reducción de los mismos para los productos sensibles.
} 
producción de bienes primarios, por otro, los países europeos tienen la oportunidad de mitigar el elevado desempleo iniciado con la crisis subprime en el 2008 con el aumento de las exportaciones de sus sectores manufactureros a esa zona del planeta aún dinámica económicamente. Las manufacturas incorporan relevante mano de obra al largo de toda la cadena productiva.

\section{PROBLEMÁTICA RELATIVA A LA CLÁUSULA SOCIAL Y MEDIOAMBIENTAL}

Las relaciones políticas y económicas entre la Unión Europea y América Latina son indudablemente importantes $\mathrm{y}$, en tiempos de crisis económica mundial, verdaderamente estratégicas.

Sin embargo, la adopción de condicionalidades basadas en la protección social, en el respecto de los derechos humanos y laborales y en la protección del entorno medioambiental por parte de la Unión Europea, genera un incremento de costos inaceptable para muchas empresas ubicadas en países en desarrollo e interesadas en beneficiarse de los regímenes arancelarios preferenciales ofrecidos por la Unión Europea.

Los gobiernos de los países en desarrollo sistemáticamente afirman que las condicionalidades responden mucho más a un propósito proteccionista, constituido por barreras comerciales camufladas de propósitos políticamente correctos que a un genuino interés por mejorar la situación laboral, social o medioambiental de países ajenos a la Unión Europea.

Efectivamente, la inclusión de la denominada "cláusula social" no soluciona los problemas de los trabajadores en los países en desarrollo ni la "cláusula verde" los problemas generados por la degradación medioambiental. Tampoco ofrecen alternativas económicas para sustituir esas precarias situaciones.

En relación a la protección del medioambiente es importante observar que el comercio de créditos de carbono autorizado por el Protocolo de Kioto o el rechazo de los países ricos en relación a la creación de un fondo de reserva económica durante la Conferencia de desarrollo sostenible de Naciones Unidas en junio de 2012 (Río+20) han reforzado las teorías según las cuales la inclusión de esas cláusulas cumplen solamente el propósito de dificultar el acceso de los bienes y servicios originarios de los países más pobres.

Ese argumento lógicamente no es compartido por las autoridades comunitarias que afirman combatir la vulnerabilidad derivada de la falta de diversificación e insuficiente integración en el sistema de comercio internacional de los países en desarrollo. 


\section{LAS EXTERNALIDADES DERIVADAS DE LA INCLUSIÓN DE LA PROTECCIÓN SOCIAL Y MEDIOAMBIENTAL EN EL SISTEMA DE COMERCIO INTERNACIONAL}

La protección social y medioambiental genera externalidades positivas (adopción de normas jurídicas beneficiosas para el ser humano y el medioambiente relativamente a los países que han incorporado los acuerdos internacionales antes mencionados a sus respectivos ordenamientos jurídicos) como también externalidades negativas (proteccionismos mediante la adopción de barreras comerciales no arancelarias, elevación de costos para las empresas ubicadas en países en desarrollo, ralentización de la dinámica industrial y económica por la adopción de metas de reducción de emisión de gases de efecto invernadero por los gobiernos, reducción de márgenes de lucro en virtud del incremento de la protección social etc.).

Ambas externalidades pueden ser asociadas al patrón de protección social y medioambiental adoptado en el ámbito del SPG europeo. Evaluar las consecuencias resultantes debe constituir objeto de profunda reflexión por las partes involucradas, incluyendo la sociedad civil.

De cualquier modo, no constituye novedad alguna que las barreras no arancelarias al comercio pueden asumir variadas formas, casi todas con apariencias legales: certificados de sanidad animal, certificados fitosanitarios, burocracia excesiva etc.

En este sentido, el establecimiento unilateral, por parte de la Unión Europea, de condiciones asociadas a la incorporación y efectivo cumplimiento de instrumentos internacionales relativos a la protección social y medioambiental por parte de los países en desarrollo, podría también constituirse en un importante y reprochable obstáculo al libre flujo internacional de bienes y servicios, que la Organización Mundial del comercio pretende asegurar.

Evidentemente, los sectores exportadores afectados de los países en desarrollo no pueden demostrar con facilidad que la protección social o medioambiental constituye una barrera al comercio internacional. Por otro lado, los países desarrollados tampoco pueden demonstrar con facilidad que no se trata de proteccionismo.

Existe aquí un enorme conflicto de intereses entre países desarrollados y en desarrollo y un empleo ambiguo del derecho internacional. Será la finalidad pretendida, inmensamente mezclada con los intereses políticos y estratégicos, que proporcionará la base coherente de la argumentación, a favor o en contra del actual sistema adoptado por el SPG europeo.

\section{REFERÊNCIAS BIBLIOGRÁFICAS}

Libro Verde sobre la promoción y la información de los productos agrícolas: 
una estrategia de elevado valor añadido europeo para promover los sabores de Europa. Bruselas, 14.7.2011

$\operatorname{COM}(2011) 436$ final.

http://europa.eu/documentation/officialdocs/white-papers/index_es.htm

Libro Verde: Política de desarrollo de la UE en apoyo del crecimiento integrador y el desarrollo sostenible. Mejorar el impacto de la política de desarrollo de la UE. Bruselas, 10.11.2010. $\operatorname{COM}(2010) 629$ final. http://europa.eu/documentation/officialdocs/white-papers/index_es.htm

Libro Blanco. Adaptación al cambio climático: Hacia un marco europeo de actuación. Bruselas, 1.4.2009

$\operatorname{COM}(2009) 147$ final.

http://europa.eu/documentation/officialdocs/white-papers/index_es.htm y http://eurlex.europa.eu/Notice.do?val=334295\%3 Acs\&lang=es\&list $=334295 \% 3$ Acs $\% 2 C$ $\&$ pos $=1 \&$ page $=1 \& \mathrm{nbl}=1 \&$ pgs $=10 \& \mathrm{hw}$ ords.

Libro Verde de la Comisión al Consejo, al Parlamento Europeo, al Comité Económico y Social Europeo y al Comité de las Regiones. Adaptación al cambio climático en Europa: Opciones de actuación para la UE. Bruselas, 29.6.2007 COM(2007) 354 final. http://europa.eu/documentation/officialdocs/white-papers/index_es.htm

Libro Verde sobre la utilización de instrumentos de mercado en la política de medio ambiente y otras políticas relacionadas Bruselas, 28.3.2007 $\operatorname{COM}(2007) 140$ final. http://europa.eu/documentation/officialdocs/white-papers/index_es.htm

Libro Verde. Una Europa Global. Instrumentos de defensa comercial europeos en una economía global en transformación. Libro Verde para consulta pública. Bruselas, 6.12.2006 $\operatorname{COM}(2006) 763$ final. http://europa.eu/documentation/officialdocs/white-papers/index_es.htm

Libro Verde. Modernizar el Derecho laboral para afrontar los retos del siglo XXI. Bruselas, 22.11.2006 COM(2006) 708 final.

http://europa.eu/documentation/officialdocs/white-papers/index_es.htm

Libro Verde. Estrategia europea para una energía sostenible, competitiva y segura. Bruselas, 8.3.2006 COM(2006) 105 final.

http://europa.eu/documentation/officialdocs/white-papers/index_es.htm

Sistema de preferencias arancelarias generalizadas. Miércoles 13 de junio de 2012 - Estrasburgo.

http://www.europarl.europa.eu/sides/get Doc.do?pubRef=-//EP//TEXT+TA+P7TA-20120241+0+DOC+XML+V0//ES. 